\title{
Review of: "Genetic Variation And Association Mapping of Phenolic, Flavonoid Content And Antioxidant Capacity In USDA Rice Mini-Core Collection"
}

\author{
Umakanta Sarker ${ }^{1}$ \\ 1 Bangabandhu Sheikh Mujibur Rahman Agricultural University
}

Potential competing interests: The author(s) declared that no potential competing interests exist.

\section{General comments}

-The manuscript presents interesting data with innovative findings that fall into the scope of the journal.

-The introduction is well written

-The methodologies seem to be sound enough to interpret the data and draw a final and complete conclusion.

-The descriptions of most methodologies are adequate to allow replication of the estimated methods properly.

-The English language is poor throughout the whole manuscript. Numerous grammatical mistakes, such as word choice, misuse of tense, sentence making, typos errors are observed throughout the MS. The language of the manuscript needs to be checked by a professional English expert.

-The whole results and discussion chapter needs to be improved.

-Elaborate the abbreviations in each Table's footnotes.

-The authors must consistent in writing the same unit throughout the whole text of the MS.

\section{Specific comments}

Extraction procedure for TPC, TFC and AA is not so exhaustive

Change "ml" to "mL". Follow this style throughout the whole MS where it exists.

Change "After $2 \mathrm{~h}$ " to "After $2 \mathrm{~h}$ ".

Change "per 100g" to "per $100 \mathrm{~g}$ ".

Change "mg GAE/100g" to "mg GAE/100 g". Numerous errors in the whole MS. Follow this style throughout the whole MS where it exists.

All Tables must be self-explanatory. Elaborate the abbreviations in each Table's footnotes.

Table 1, 2, 3, 4, and: row 1: Change "ABTS" to "antioxidant activity (ABTS)".

Change "with an averaged at $1118.8 \mu \mathrm{M}$ TEAC" to "with an average of $1118.8 \mu \mathrm{M}$ TEAC".

Change "that the AUS" to "that the AUS".

Change "high neither $(n=12)$ " to "high $(n=12)$ ". 
Change "481 rice genotypes ranged" to "481 rice genotypes".

For TFC estimation the authors used "mg CAE/100 g" in some place (results) and mg CE/100 g in some places (discussion). They must consistent in writing the same unit throughout the whole text of the MS. 